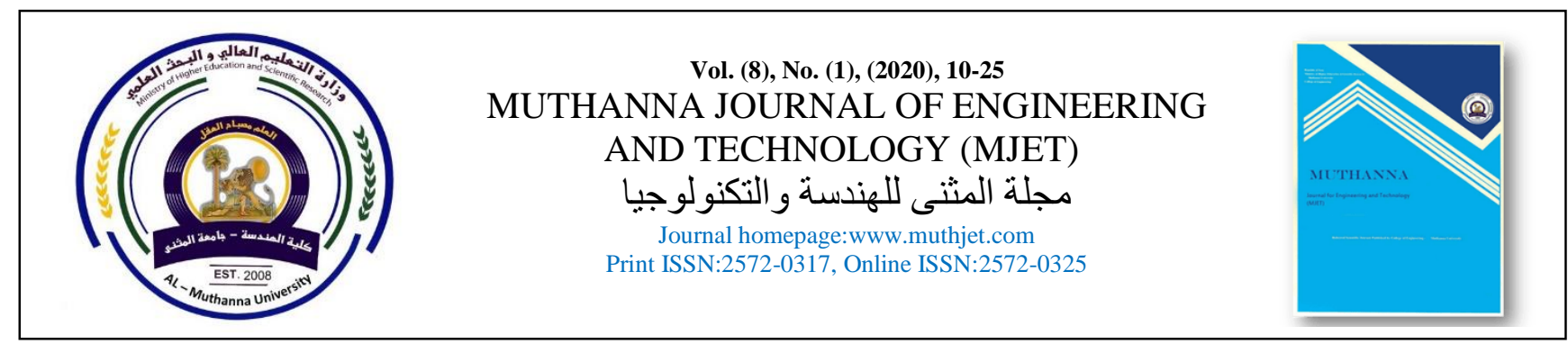

\title{
Evaluation of Some Visual Pollution Indicators in the Physical Environment of Al-Hilla City \\ Mohammad Ali Al-Anbari ${ }^{1}$, Mijed Abbas Abd ${ }^{1}$ and Alaa Hadi Obaid ${ }^{1 *}$
}

1 Collage of Engineering, University of Babylon, Hilla, Iraq;

\section{ARTICLE INFO}

Received: 23/11/2019

Accepted: 24/02/2020

Keywords

The physical environment, The physical appearance, The visual performance, the visual pollution

\section{ABSTRACT:}

The physical environment of Al-Hilla city is subject to successive developments due to changes in various economic, technological and humanitarian aspects.

These changes are accompanied by the physical appearance of the phenomenon of "visual pollution", which results from the imbalance in the visual performance of the components of the physical environment of the city, causing the sense of psychological discomfort and loss of belonging to the surrounding environment and its aesthetic is almost nonexistent.

The objective of this research is to evaluate the state of the visual components of the physical environment of Al-Hilla city, through an analytical field study of the visual impact indicators of the state of the physical environment of Al-Hilla city, and comparing it with the visual performance standards, to determine the defect and gap. For research purposes, the field study was conducted for the most important street in the city center, which is Imam Ali Street, on the basis of which the visual pollution ranges were determined, and therefore the recommendation of making the right decisions (whether at the level of implementation or field monitoring) is necessary in order to reduce or mitigate the phenomenon of visual pollution) to improve the visual performance of the street in particular, and the physical environment of Hilla city in general . 


\section{Introduction:}

The physical environment in any urban complex consists of two elements, namely the natural environment and the built environment, which are defined as follows:

Natural environment: This environment includes the objects that does not related to humans in its existence or usage. For example, desert, seas, climate, terrain, surface water, groundwater, plants' and animals' life, and the natural environment with a direct or indirect impact on the life of any living group of a plant, animal or human being [1].

The built environment: - It consists of the physical infrastructure constructed by human in addition to the established social systems and institutions by human being as well. Thus, the built environment can be observed through the way in which societies organized their lives, which changed the natural environment to serve human needs, and the built environment includes land uses for agriculture, residential regions, and exploration for natural resources, in addition to industrial areas, commercial centers, schools, institutes, roads ... etc. [1].

The environment, both natural and built, is an integrated framework that includes the globe, or the transfer of the life planet, and what affects other components of the universe. The contents of such framework is not rigid, but it is permanently reactive and influential and human itself is one of the components that interacts with the environment and other human beings. This comprehensive understanding was reported by Mr. U Thant, the Secretary-General of the United Nations who said "We like it or not, we travel together on a shared planet... We have no reasonable alternative but to work together to make it an environment in which we and our children can live a safe and secure life"[1]. This requires the human being, the only sane person of life, to deal with the environment in kindness and compassion, investing without damage or destruction. Perhaps, the understanding the environment and its components and their interrelationships can assist humans in finding and improving a better place for their lives and their generations afterwards [1].

The components of the physical environment (natural and built) in a city, are planned and designed in homogeneity, to achieve the highest efficiency of its spatial, functional, and visual performances, and therefore, it is a prerequisite for a city to be sustainable, and serve its current and future generations.

The triple location, function and shape, constitute the basic tools to control the physical environment and raise its performance through the planning and design of these components taking into account the general visual impact arising from them that can enhance the performance efficiency of the physical environment.

However, achieving homogeneity in the physical environment represents a complex issue because of the overlapping effects. Many states have sought to reduce the negative impacts on the physical environment by enacting legislation and regulations to achieve homogeneity.

For example, in the early 1980s, the British government called for easing some laws that have an indirect impact on safety, including those related to the aesthetic aspects of the physical environment as they are affected by taste and opinions, meaning that the aesthetic aspects of the physical environment are subjective and cannot be agreed upon among all members of society [2].

\section{Forming the physical appearance:}

The physical appearance represents the art of relationships that bring buildings together to achieve aesthetic appearance and certain qualities. The visual relations between the elements have a major role in organizing the physical appearance and crystallizing the integrated sensory image of it [3]. Kevin Lynch, in his study mentioned in his book "The image of the City", identified five key elements which all combined forming the visual composition and the formation of the city. The elements can even control the mental image formation of the city as they effect on the humans' perspectives about the city. The elements were summarized in Figure (1) and which are as follows [4]:

\section{- PATHS:}

These are the main traffic routes for the residents of a city, including the network of roads and paths with a visual significance that connects the different parts of the city as well as different footpaths. Thus, they represent lines of longitudinal spaces through which movements and different visual landscapes observations can occur, formed by different movement lines (for cars or footpaths).

\section{- EDGES:}

These are visual boundaries which determine the borders of a city, a region, or a complex as well as the borders within a city, confirming its external formation. The boundaries are either natural boundaries (mountains, seas or rivers, and trees) or human-made artificial borders (walls of buildings, roads, and bridges). Thus, they represent continuous longitudinal lines that can be perceived as boundaries between regions and their strength depends on their ability to be penetrated by movement or sight.

\section{- DISTRICTS:}

They represent the division of a city to a range of areas, including central areas and their nearby areas, and open areas, given that each area has a distinctive character, homogeneous with other areas, and has clear boundaries providing the residents with a sense of belonging to that area.

\section{- LANDMARKS:}


These are distinctive signs that enable the identification of a city or its parts as well as the determination of the directions of movement and access paths within it. The landmarks can be either buildings or elements illustrating the formation of a city or areas and enabling the possibility of a viewer to identify their location and direction in a city or a region. The signs are either external being observed from outside the urban block of a city, or internal being seen by roaming around a city.

- NODES:

These are fields and squares areas in addition to the contact points. They represent the centers of movement, transmission, assembly, and activities in a city, and are reflected in the presence and formation of assembly points.

\section{Visual Performance:}

Brolin has divided the characteristics that affect the homogeneity of the physical appearance into two parts:

1-General characteristics: These are the characteristics that are familiar to most people and most modern contemporary designs have criteria for regulating those characteristics, providing a sense of attachment to the original [5]:

o Setback from a road

o Height

o Mass: And how to configure the size of the main building ..

o Interface and directivity ratios.

o Materials.

o Appearance and visual images

o Arrangements of doors and windows.

o color.

o Size of doors and windows and their ratios.

o Scale: How a building perceives its relationship to human size.

2-Historical and non-historical characteristics: These characteristics are related to the traditional and their homogeneity and unity can be achieved by with dealing with details and processors themselves.

Brolin asserts that these characteristics are only general lines for creating unity in the physical appearance. Then, he selected a set of visual properties for checking the continuity of a range of buildings and homogeneity of the physical appearance [5]. These are as follows:

-Construction Line: The organization of the construction line represents the basis of the visual continuity of a group of buildings. The facades lines along a road have a direct effect on the way by which buildings are observed and their relation to other buildings. The unification of the construction line plays a significant role on the personality and identity of a road network, strengthening the sense of place and indicating the importance of regulating the distance of setback of buildings and its impact on the formal homogeneity.
-Height of buildings and skyline: The issue of buildings height and its relationship to the skyline represents one of the most prominent visual issue of a range of buildings. The differences between building heights break the skyline and affecting the formal homogeneity of the physical appearance.

-Unit Width: Unifying the width of building units contributes to the cohesion and homogeneity of buildings.

-Quality of details and materials: The use of local materials can provide a strong sense of visual unity for the city, since its use in new buildings contributes to ensuring visual continuity. Building construction with different materials can lead to breaking homogeneity, lines, color and texture.

-Ratio between window's openings to the wall: The regularity of openings for a group of adjacent buildings contributes in achieving homogeneity and visual continuity of the physical appearance, while the variance in the openings lead to inhomogeneity and break the continuity of the physical appearance. -Space containment: In order to achieve homogeneity, attention should be given to the formal characteristics of the surrounding buildings and to avoid buildings with weak characteristics or visual homogeneity.

\section{Visual Pollution:}

Visual Pollution is defined as the entire irregular formations, which are mostly found in natural and built environments [6]. Visual Pollution is a term used for the unattractive visual elements, which are all types of different landscapes surrounding humans, such as unexamined buildings, informal architecture, and random advertisements.

The visual pollution is also defined as anything that can adversely affect the visual image and distract it including unaesthetic, and heterogeneous views in addition to elements distorting the aesthetic form.

Visual pollution encompasses all environmental elements that are socially unsuitable or unacceptable. It is a changing value of the environment based on the cultural background of the viewer and society. There are many sources of visual pollution in contemporary cities, starting from contiguous contradictory architectural patterns to distortion of the visual vision of by the use of many banners and advertisements in addition to the dazzling use of lights, colors and shapes. Visual pollution generally appears in the physical environment, including buildings, streets and landscape. The visual pollution can be easily observed in cities, particularly large and crowded ones in the third world countries in which the visual pollution has become a common factor.

Researchers have defined pollution as "The imbalance that occurs in the visual performance of the physical environment with all its natural and built components which reduces the aesthetic sense of it". Perhaps this definition is the most comprehensive and the closest to the methodology of this research used in the case of the study. 
The features of the visual pollution can be determined in the following points [7]:

- inhomogeneity of form, proportions, color, and movement.

- All that can reduce cleanliness, safety, and authenticity.

- The presence of an element contrary to environmental features and considers intruder on the environment.

- All that adversely impact on the public taste, including drawing, signal, or speech.

- All factors that reduce the integration of the aesthetic sense of the environment.

The case of the study and the research objective:

The physical environment of Al-Hilla city is subjected to successive developments as a result of changes in various economic, technological and humanitarian aspects. Along with these changes, the physical appearance is exposed to the phenomenon of "visual pollution" which results from the imbalance in the visual performance of the components of the physical environment of the city, causing a psychological discomfort and loss of belonging to the environment as well as being virtually unaesthetic.

Therefore, this research aims to evaluate the state of visual aspects of the components of Al-Hilla city physical environment, through an analytical field study of the visual impact indicators of these components .

\section{Research Methodology:}

To achieve the objective of the research, analytical field study was adopted for comparing the visual impact indicators of the state of the physical environment of the Al-Hilla city with the visual performance criteria. This was to establish the defects on which the visual contamination is determined, and for reaching to several conclusions and recommendations to reduce this phenomenon.

For research purposes, the field study was conducted on the most important road in the city center, which is Al-Imam Ali Street. Also, in order to achieve the accuracy in field surveys, the street was divided into three sections A, B, C, and each section with two sides right and left, as shown in the following figures numbered (2, 3, 4, and 5):

Field survey structure form of Al-Imam Ali street:

Table (2)show the field survey structure form of Al-Imam Ali street in Hilla city, which had been achived in four months , beginning from 1-2-2019.

\section{Results analysis:}

From the field survey, it can be indicated that there are three sections in the roads highlighted on the areo-graphs of the road varying from one another in the fault present in the visual performance, these sections are section $\mathrm{A}$, section $\mathrm{B}$, and section $\mathrm{C}$. The visual performance varies from (100)\% given five points $(\bullet \bullet \bullet)$ which means high visual performance i.e. very low visual pollution to (20)\% given one point $(\bullet)$ which means very low visual performance i.e.very high visual pollution (because of final loss for some of the indicators necessary for roads in visual pollution)

For table (3) section (A), the main functional organisation of the sidewalk is missing due to high variations of functions nearby such as business stores, car parks and the openings of the theses parks which is linked with that of old residential blocks with the section being close to Al-Handiya bridge and the old market with the performance of the other indicators being inefficient

In terms of table (4) section (B), the visual performance is approximately lower than the results of the front side of road buildings, though the performance is very low for the rest of the indicators and has not reached the accepted level.

In terms of table (5), it is noticed that there is is a substantial decline in visual performance which means that visual pollution is very high in section (C). The reason behind that is the presence of commercial advertisements in a significant manner that doesn't meet the criteria adopted in the research. This leads to visual pollution in all of its indicators from one side and obstructing the fluency of the pedestrian movement from the other side.

\section{Conclusions:}

It would be obvious to conclude the followings:

1- Buildings surrounding the roads:

The decline in the level of visual pollution in the building elevations surrounding the roads is related to the presence of formality in structure, design style, and the building materials utilized in its construction with the presence of correlation between them in terms of colours (similarity and colour gradations). In term of the heights of the buildings surrounding the road, they should have relatively similar heights to define the road and unified with the ground of the sidewalk or similar, and equal to the outline of the sidewalk. In term of cantilevers that extend to above the sidewalk, it should be on appropriate height and extension so it wouldn't exceed the width of the sidewalk with having appropriate and correlated colors and measurements and finishing materials having relatively similar colors, type, texture and not affecting the driver's eye.

2- Traffic island and sidewalk dimensions: The decline in the level of visual pollution linked to unifying the height, width, and level of the sidewalk and possessing certain slopes in crossing areas. In terms of sidewalk furniture, the criteria suitable dimension should be selected that absorb the dimensions of movement lines entirely by providing safety for these lines and preventing cars, goods, and boards, etc. from acceding them.

3- Advertisement:

The decrease in the level of visual pollution is associated with organizing these advertisements in term of its dimensions, heights, and distributing 
them in appropriate and unified manners that wouldn't affect the pedestrian movement on sidewalk, or crossing of middle island with selecting suitable material in its manufacturing so it has no effect on driver's eyes and it needs to adhere to the roads criteria from the aesthetic and appearances

4- Opening Spaces of the secondary movement axes on roads:

The reduction in the level of visual pollution is associated with the definition of these outlets from the structural and design aspects and distinguishing them from the areas allocated to the sidewalk by having low levels at these areas and confirming them in architectural blocks landscape. These all are in addition to defining the quality of the outlets, if they vary from each other using the human scale and the boards or controlling the width of the outlets.

\section{Recommendations:}

It could be useful to recommend the following: The research recommends taking the right decisions (on the executive level or site monitoring) to cut off or minimize the visual pollution phenomena in AlImam Ali Street to enhance the visual performances of the street specifically, and the physical environment of Hilla city generally, so it becomes in the best way, by making the decisions and undertaking the necessary recommendation to improve the visual performances to the streets of the city by the following:

1- Inviting the authorized people responsible about decision making: (it includes the physical planning department and municipal departments, municipalities, and governance) by putting laws and instructions that prevents the constructions that do not adhere to street criteria, also prevent the bad use of the building, sidewalk, and street which spoil and pollute their appearance and commercial uses.

2- Inviting the planning, designing and execution authorities: (involves the planners, and engineers for all specialties and contractors) to execute the street criteria according to the quality and choose the upper or medium-level, without resorting to the minimum standard to abbreviate the activities lines of the roads, sidewalk, and middle island, so take into account the absorption of the increase in human densities.

3- Inviting the benefiting groups: (includes the roads users who are the people lived in and around it and the owner of the stores and drivers passing it as well as pedestrian) to follow the specific instructions associated with the constructions and utilization and working on organizing the sidewalk and not exceeding it by displaying goods, advertisements and stalls in the way that obstacle the fluency of other services and distort the road appearance in general, and to keep the continuity of the road maintenance and performance its function in the best manner and cooperate with other groups in that, in addition to the use of the social activities in the pedestrian intersections with roads to increase the daily utilization hours of the roads.

\section{Reference:}

[1] -

http://amenagementa.blogspot.com/2016/01/milieuenvironment-Urban-Ecology.html[CrossRef].

[2]- Levy, John (1994)," Contemporary Urban Planning", Third Edition; Prentice - Hall, Inc. p.243/250.

[3]-Cullen G. (1961), "Townscape", the Architect Cultural Press. London., p.17.

[4]- Lynch, Kevin (1960). "The Image of the City",The MIT Press. ISBN 0-262-62001-4.

[5]- Brolin B. (1980), "Architecture in context: Fitting new buildings with old", Van No strand Reinhold company, New York. [6]- Yilmaz, D. (May 2011), "In the Context of Visual Pollution: Effects to Trabzon City Center Silhoutte". The Asian Social Science Journal., 7((5)), 99 [CrossRef].

[7]- Mahjoob.Dr Yassar/ published in 9/7/2010

"Information and articles and lectures about architecture and construction ".in Yasser Mahgoub/(https://kenanaonline.com/users/YasserM ahgoub/posts/135017[CrossRef].

[8]- Nicholas and Bousmaha Baiche Neufert (2000),"Architect 'Data"/Third Edition,Williman[CrossRef].

[9]- Al-Haydari, Ali (1986), "lectures in Housing/ Germany criteria"[CrossRef].

[10]- Ministry of Municipal and Rural Affairs , "Guide of planning criteria for commercial services in cities/ guide of sidewalk design"/ United Arab Saudia/ $1426 \mathrm{H} /$ first press/ Ryiad website (WWW.alrid,ogov,sa) [CrossRef]. [11]- Babylon Province (2011), "Physical planning office criteria[CrossRef]".

[12]- The National Organization for Civilization Coordination (2010) "Guidance / Foundations and standards for civil coordination for advertisements and banners" first edition / Arab Republic of Egypt[CrossRef]. 


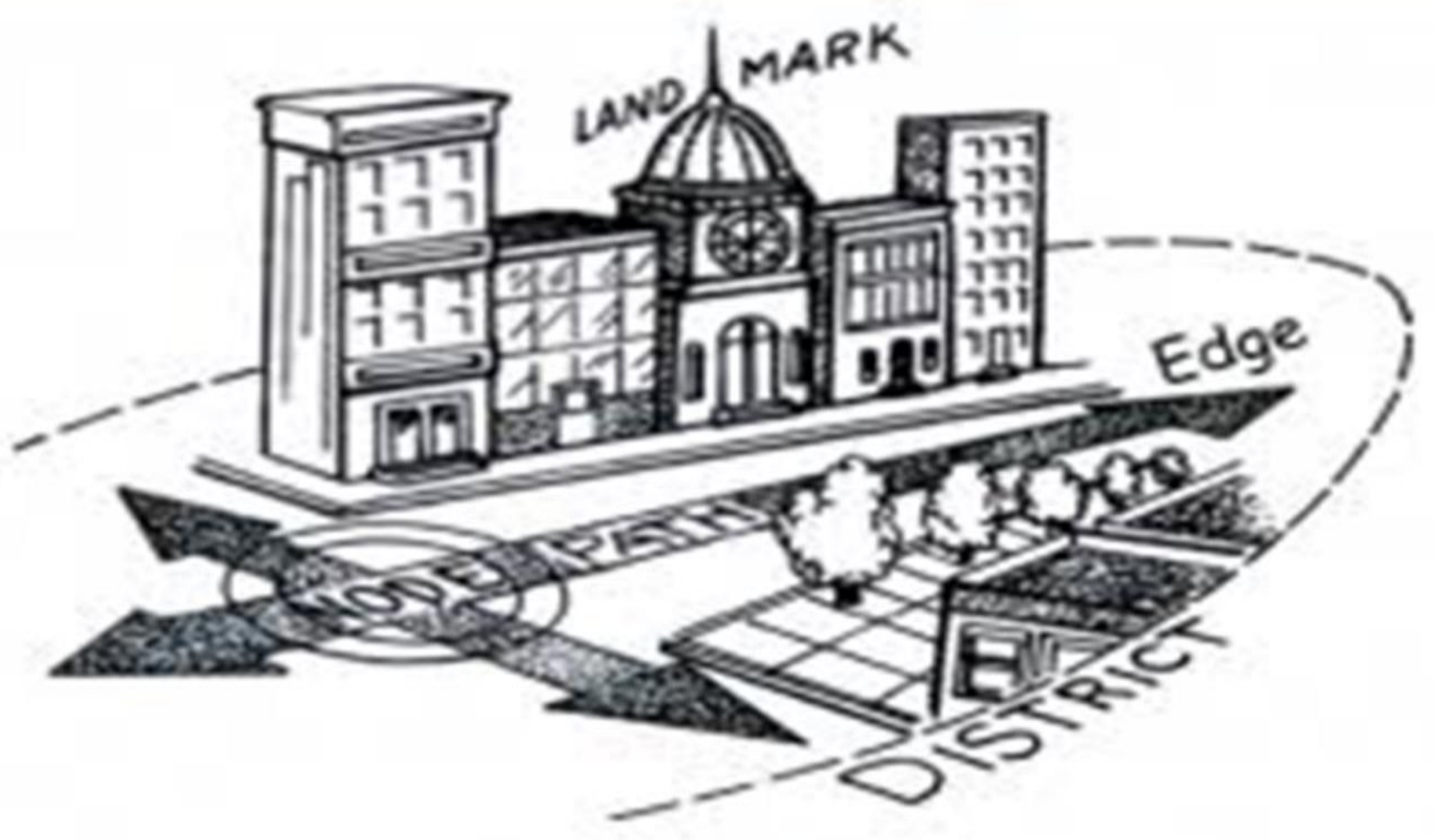

(Lynch, 1960)

Figure (1): Elements of physical appearance of Kevin Lynch

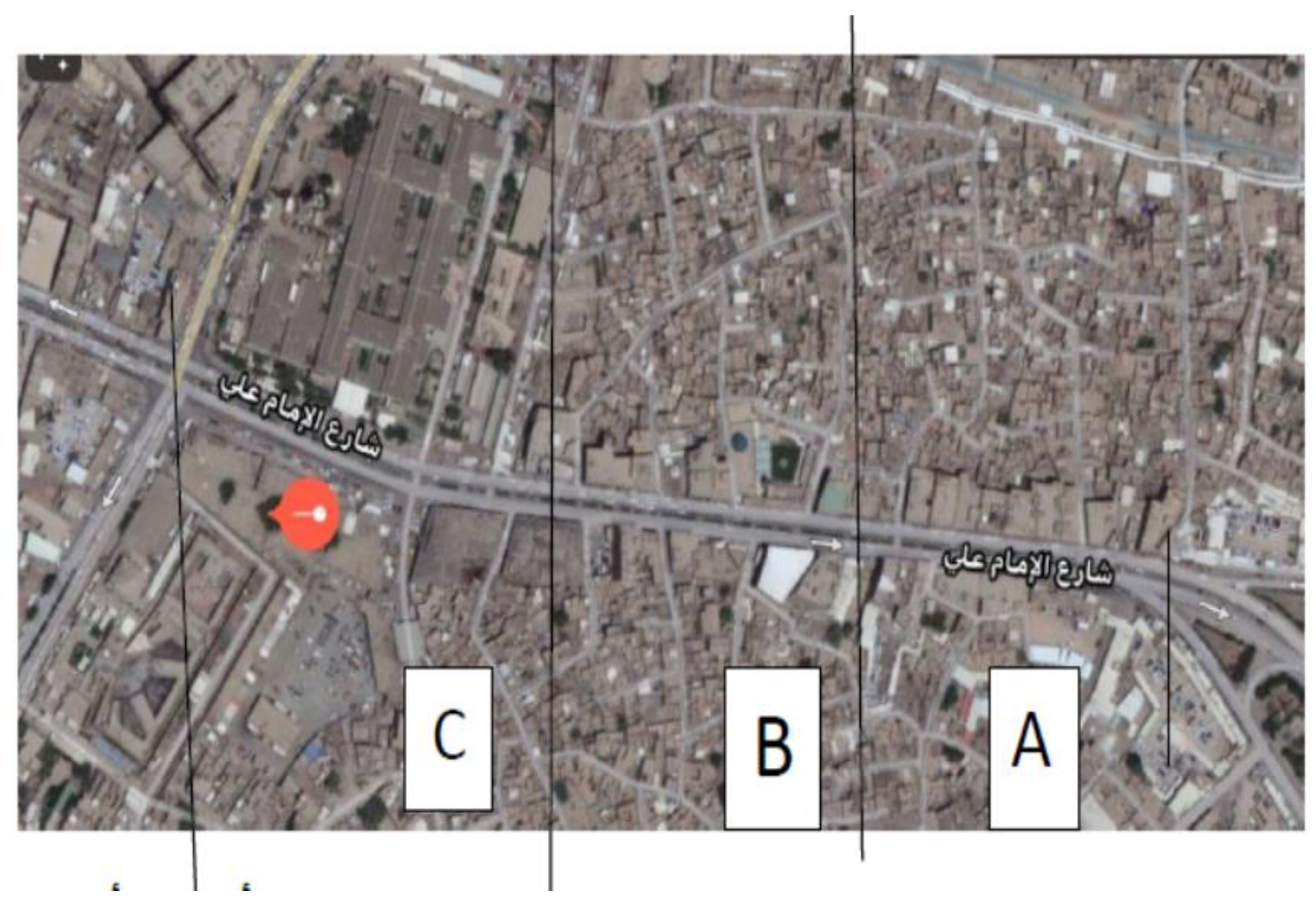

Figure (2): The aerial image and the division of the street into three sections to facilitate the process of reading the visual performance of Al-Imam Ali Street. 


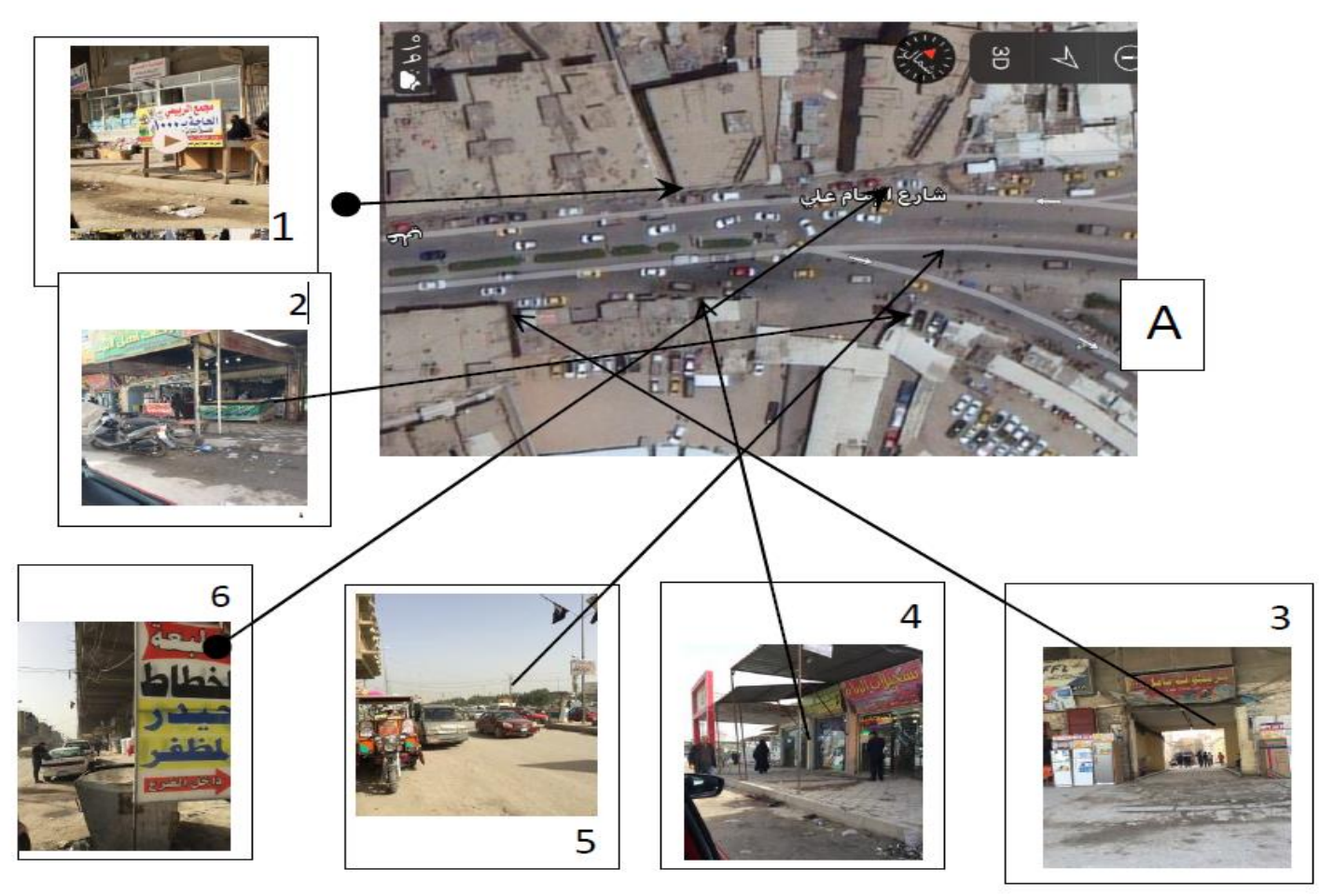

Figure (3): Images of defects in the visual performance standards of Al-Imam Ali Street in section (A)

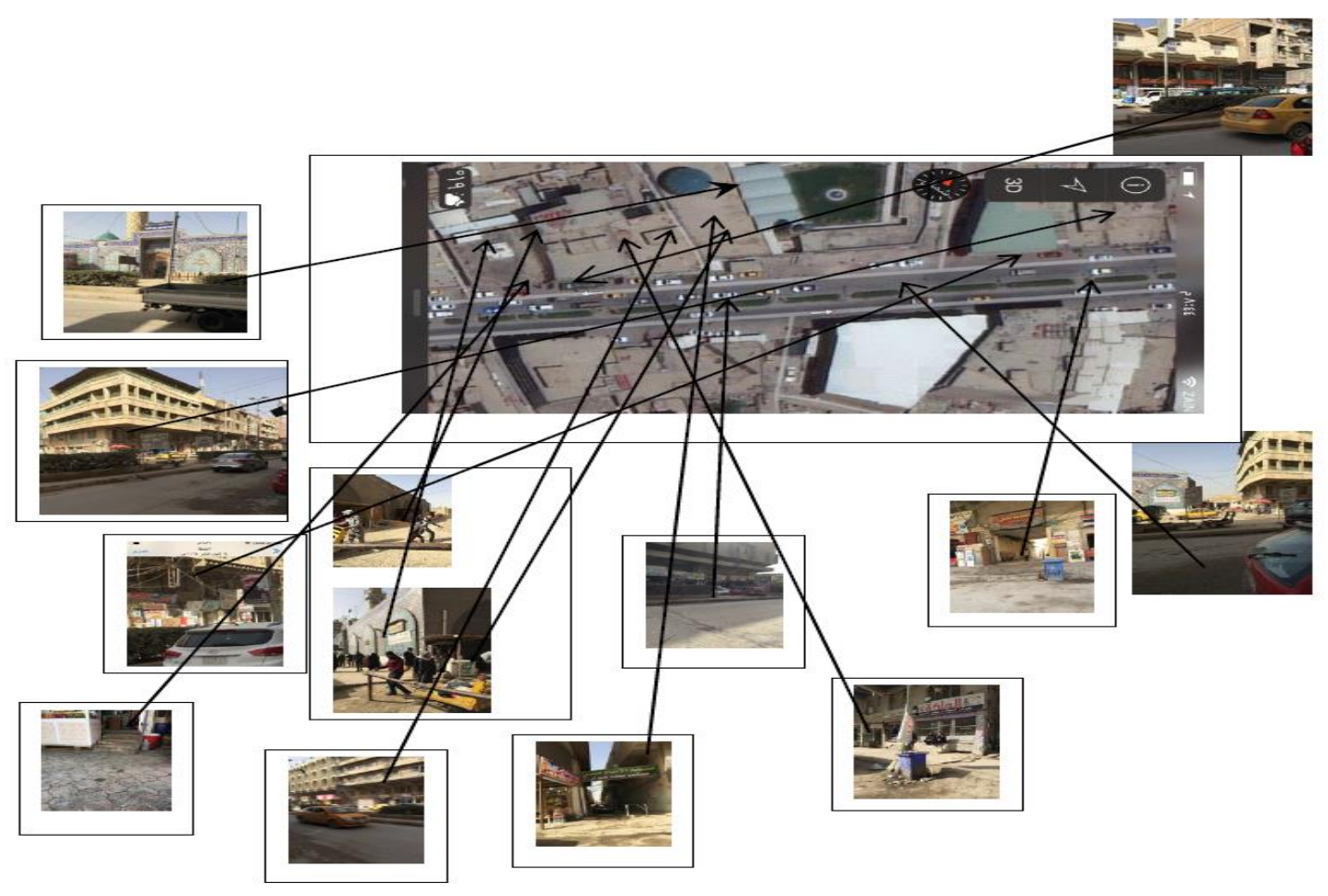


Figure (4): Images of defects in the visual performance standards of Al-Imam Ali Street in section (B)

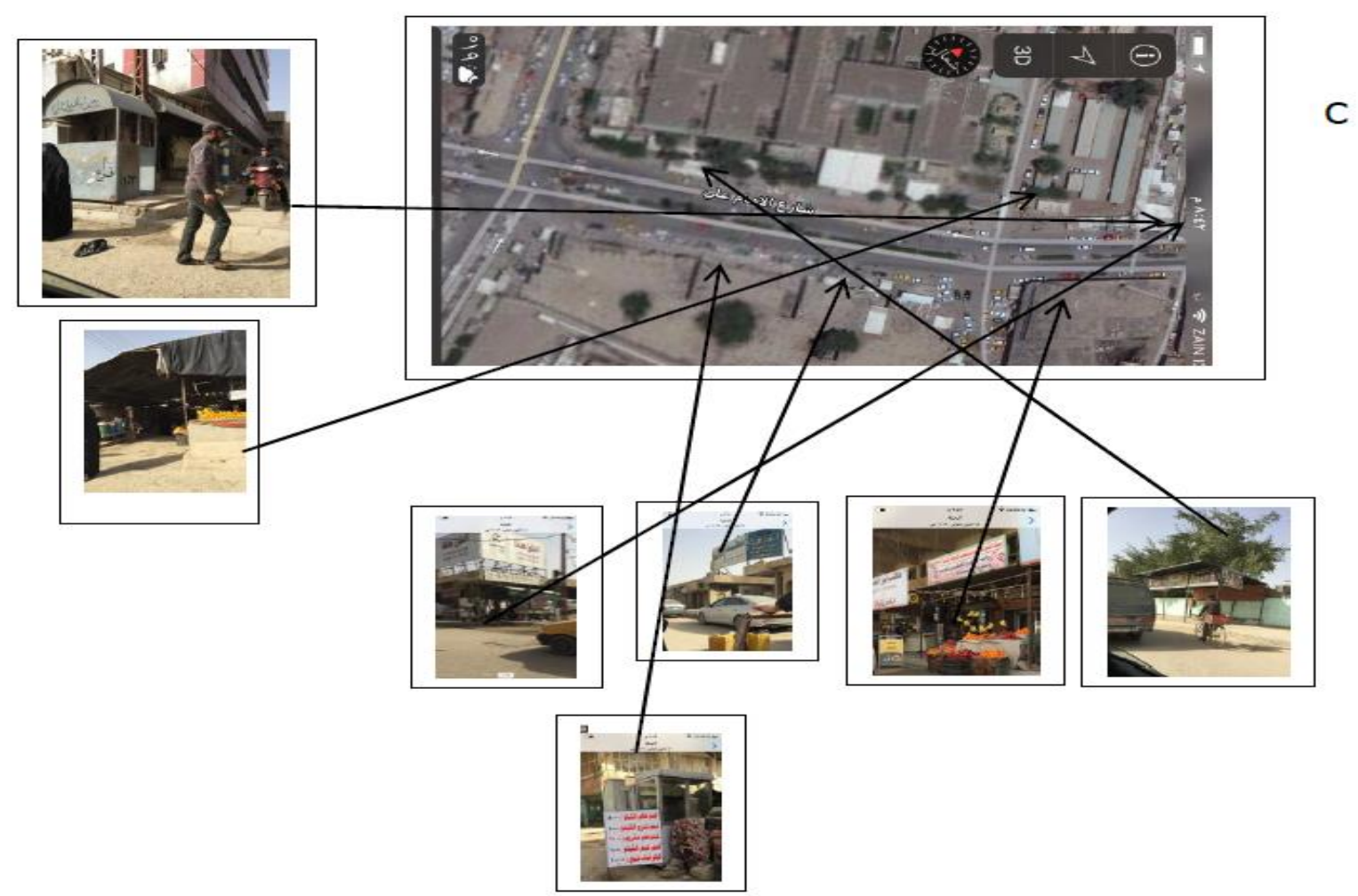

Figure (5): Photos of defects in the visual performance standards of Al-Imam Ali Street in section $(\mathbf{C})$

Table (1): The method of measuring the visual performance of Al-Imam Ali Street using a method derived from the five-level Likert scale.

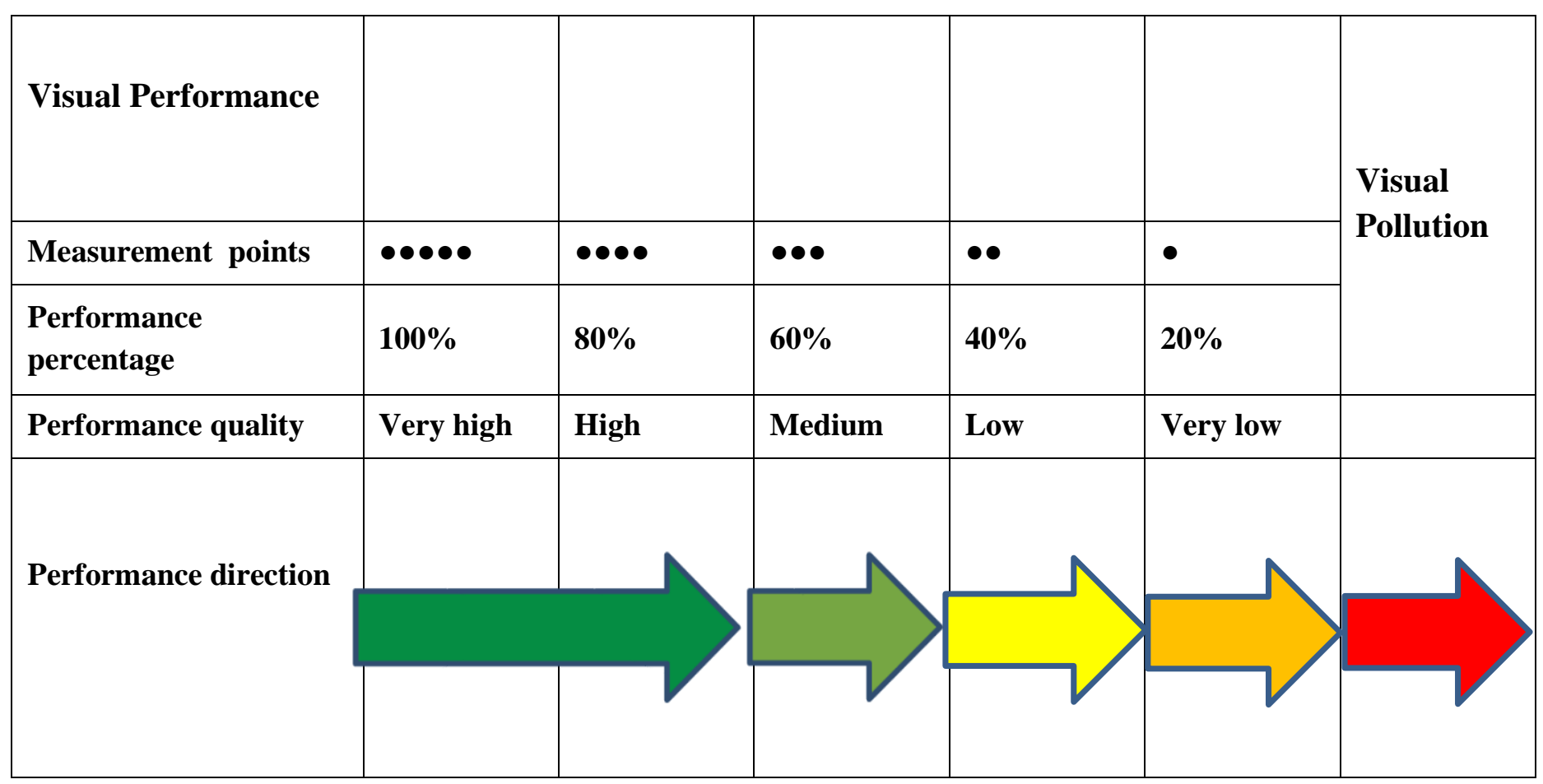


Table (2): The field survey structure form of Al-Imam Ali street

\begin{tabular}{|c|c|c|c|c|c|}
\hline \multicolumn{2}{|l|}{ Categories } & Indicators & Required criteria & $\begin{array}{l}\text { Measurement or } \\
\text { description of } \\
\text { current condition }\end{array}$ & Assessment \\
\hline \multirow{3}{*}{\multicolumn{2}{|c|}{ Properties of the street [8] }} & $\begin{array}{l}\text { Width of the whole street } \\
\text { with pavement }\end{array}$ & From $(22.5-34 \mathrm{~m})$ & & \\
\hline & & Width of vehicle street & From $(7.5-23 \mathrm{~m})$ & & \\
\hline & & Width of middle island & From $(2-5 \mathrm{~m})$ & & \\
\hline \multirow{2}{*}{\multicolumn{2}{|c|}{$\begin{array}{l}\text { The street type is commercial } \\
\text { Note/ the assessment is for all } \\
\text { sections }\end{array}$}} & $\begin{array}{l}\text { Time for full utilization } \\
\text { of the roads }\end{array}$ & $\begin{array}{l}\text { Within (24) hours or } \\
\text { according to the } \\
\text { commercial function with } \\
\text { the presence of late- } \\
\text { working shops or mixed- } \\
\text { use. }\left[{ }^{\natural}\right]\end{array}$ & & \\
\hline & & Vehicle's speed & $\begin{array}{l}\text { Less than or equal to (50) } \\
\mathrm{k} / \mathrm{h}\end{array}$ & & \\
\hline \multirow{15}{*}{$\begin{array}{l}\text { Buildings } \\
\text { adjacent and } \\
\text { around the } \\
\text { street }\end{array}$} & \multirow{15}{*}{$\begin{array}{l}\text { Building } \\
\text { facades }\end{array}$} & \multirow{9}{*}{$\begin{array}{l}\text { Facade design } \\
\text { Convergence in form, } \\
\text { proportions, color, } \\
\text { movement, similarity } \\
\text { and consistency. }\end{array}$} & \multirow{6}{*}{$\begin{array}{l}\text { 1- It should be a mixture of } \\
\text { similarity and consistency } \\
\text { among them in terms of } \\
\text { colors, design and } \\
\text { proportional with the } \\
\text { traditional style, whether } \\
\text { near or within the old } \\
\text { heritage even in some } \\
\text { similarities }[10] .\end{array}$} & & \\
\hline & & & & & \\
\hline & & & & & \\
\hline & & & & & \\
\hline & & & & & \\
\hline & & & & & \\
\hline & & & \multirow{3}{*}{$\begin{array}{l}\text { 2- The cantilevers should } \\
\text { be equal and their width } \\
\text { should not exceed the } \\
\text { width of the pavement } \\
\text { [11]. }\end{array}$} & & \\
\hline & & & & & \\
\hline & & & & & \\
\hline & & $\begin{array}{l}\text { Building material } \\
\text { (structural reinforced } \\
\text { concrete) }\end{array}$ & $\begin{array}{l}\text { Near or the same for } \\
\text { avoiding the differences in } \\
\text { contraction or extension of } \\
\text { building materials } \\
\text { especially for adjacent } \\
\text { buildings [10]. }\end{array}$ & & \\
\hline & & \multirow{5}{*}{$\begin{array}{l}\text { finishing materials of } \\
\text { buildings' facades in } \\
\text { terms of: } \\
\text { The presence of } \\
\text { extraneous structural } \\
\text { elements extraneous or } \\
\text { not, reflecting the }\end{array}$} & \multirow{5}{*}{$\begin{array}{l}\text { Unified or converged to } \\
\text { clarify or enhance the } \\
\text { identity of the street } \\
\text { facades and its adjacent, } \\
\text { providing it with } \\
\text { integration and aesthetic } \\
\text { appearance }\end{array}$} & & \\
\hline & & & & & \\
\hline & & & & & \\
\hline & & & & & \\
\hline & & & & & \\
\hline
\end{tabular}




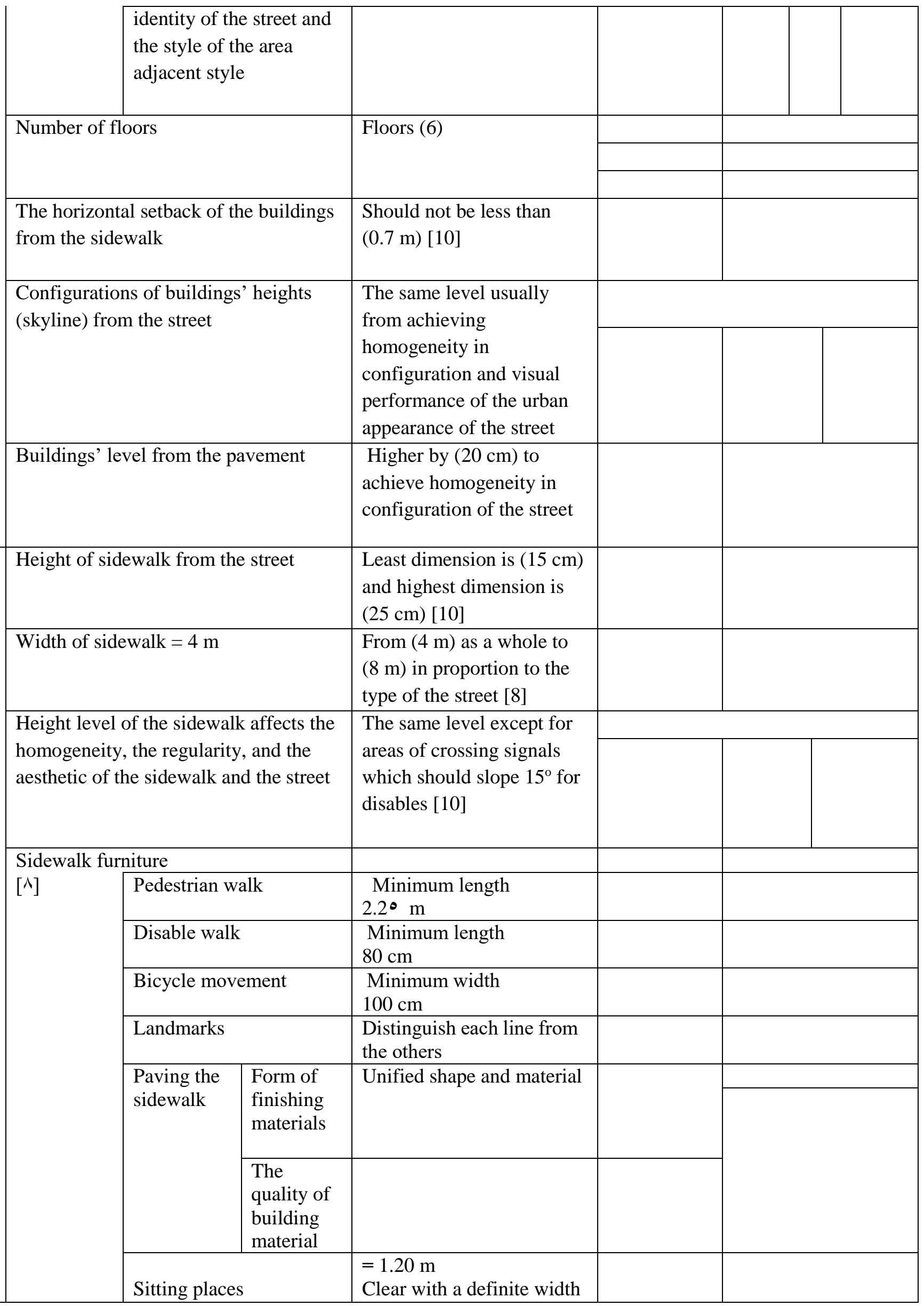




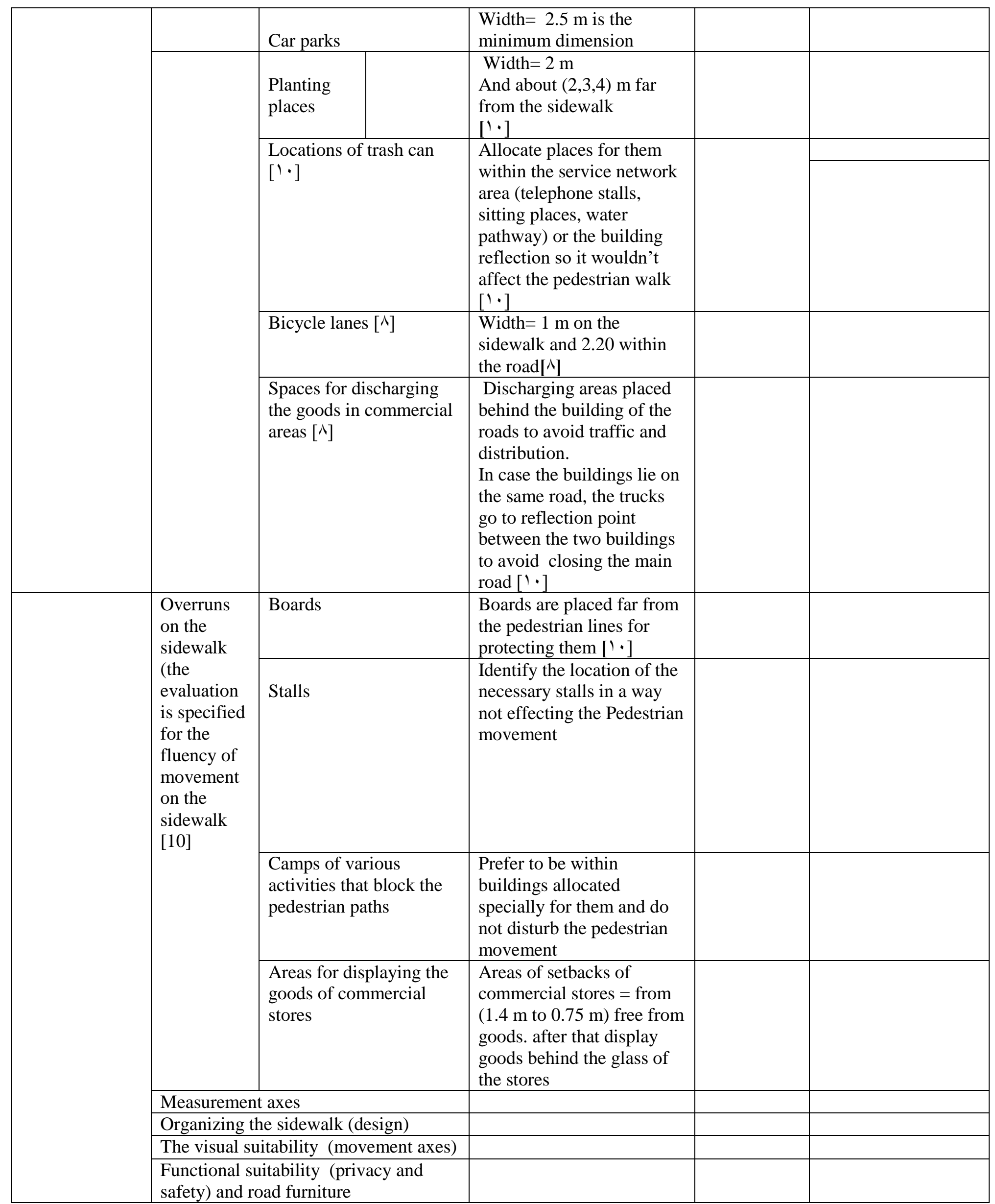




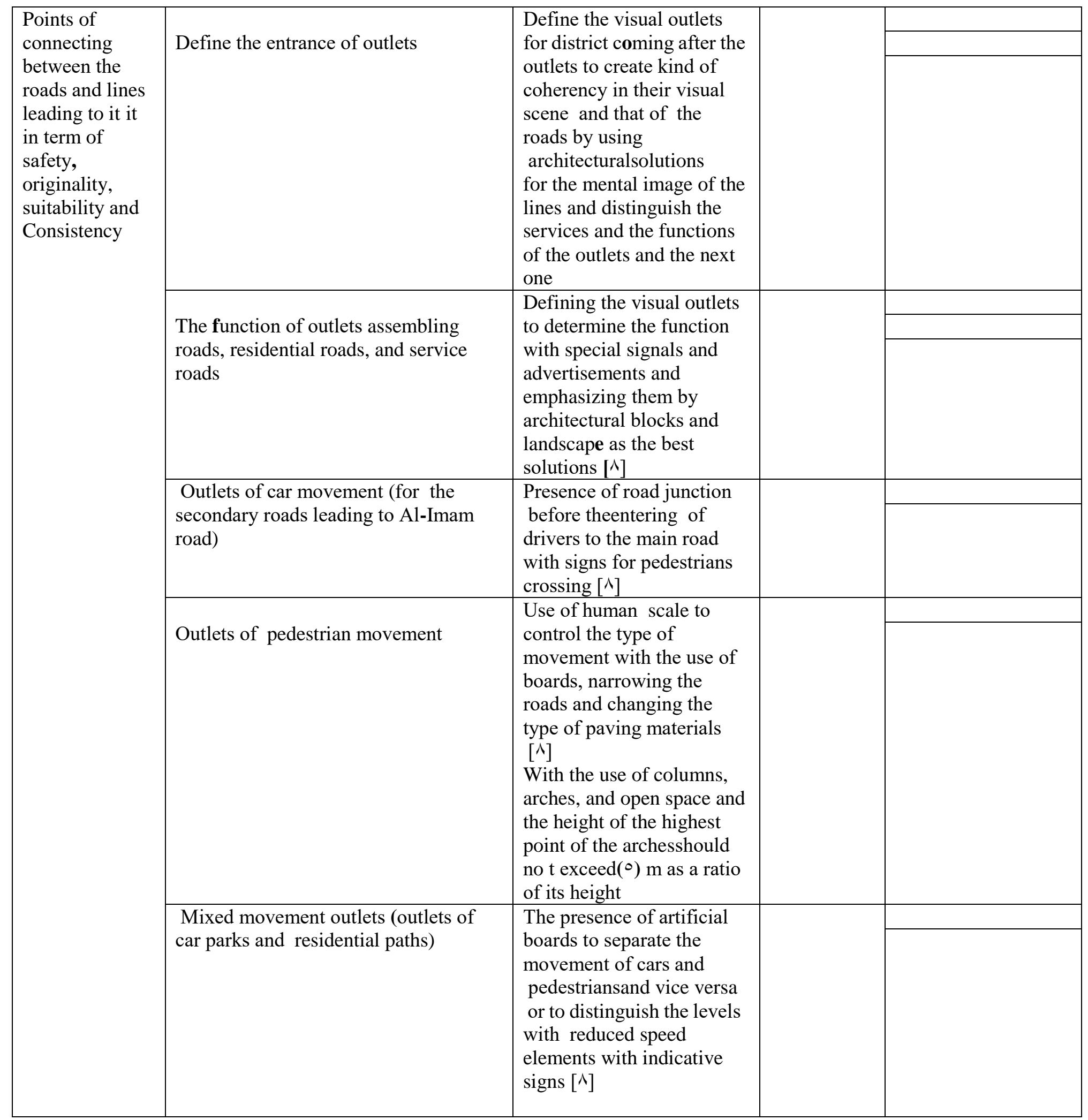


Table (3): The average measurements of the rate of visual pollution for the selected indicators for Al-Imam Ali road for section A (researcher)

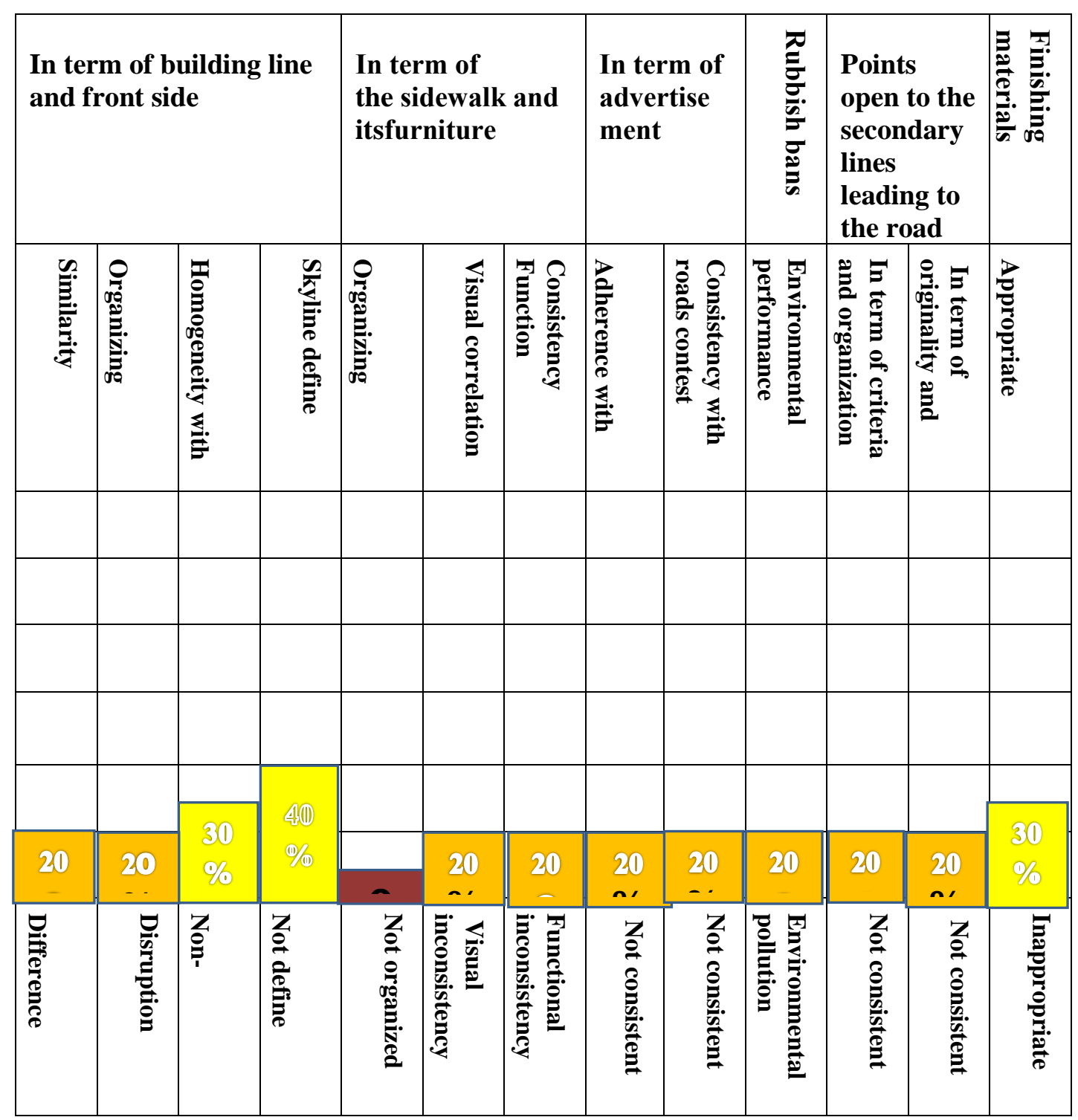


Table (4): The average measurements of the rate of visual pollution for the selected indicators for Al-Imam Ali road for section B

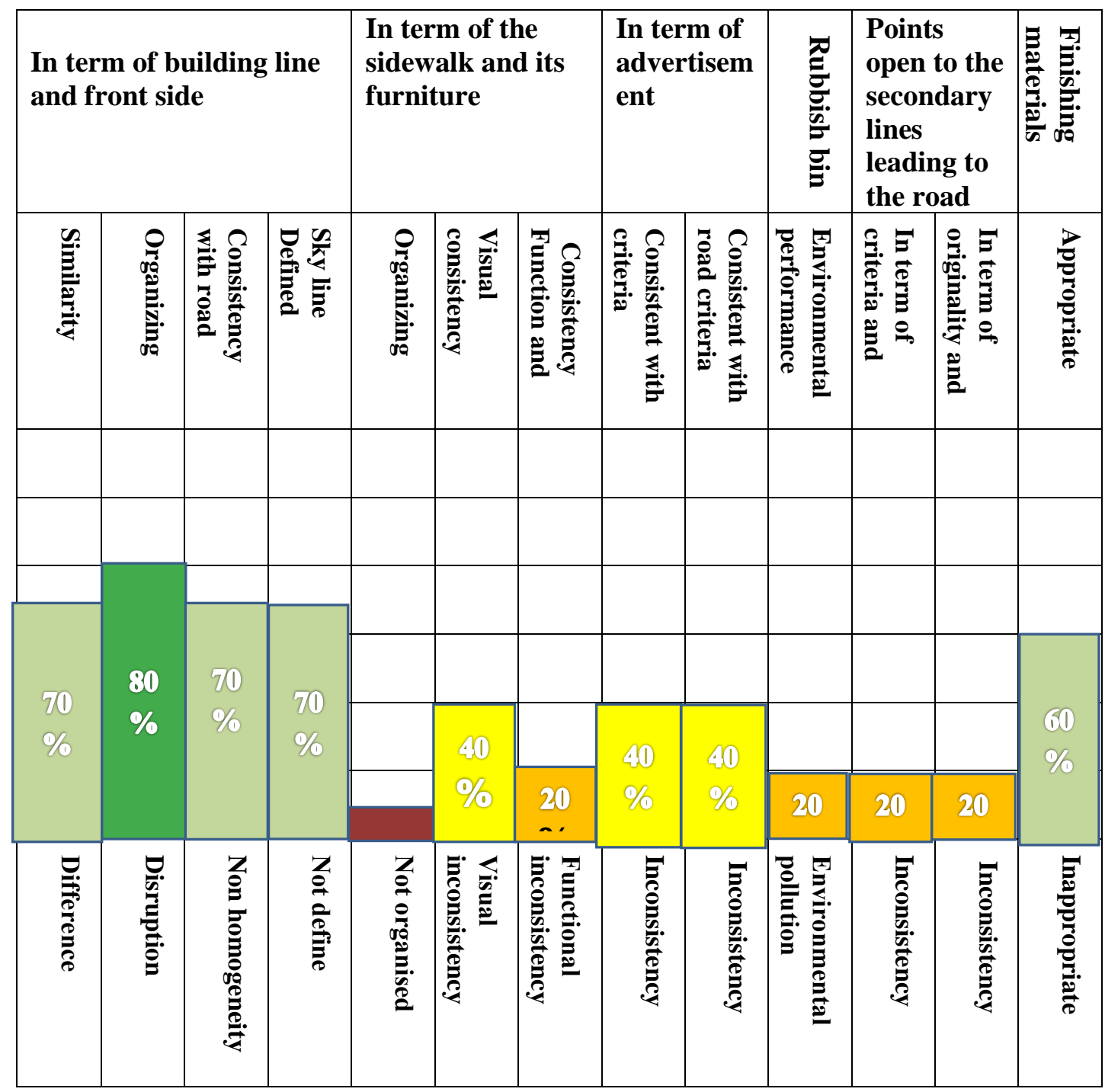


Table (5): The average measurements of the rate of visual pollution for the selected indicators for Al-Imam Ali road for section C (researcher)

\begin{tabular}{|c|c|c|c|c|c|c|c|c|c|c|c|c|}
\hline \multicolumn{4}{|c|}{$\begin{array}{l}\text { In term of building line } \\
\text { and front side }\end{array}$} & \multicolumn{3}{|c|}{$\begin{array}{l}\text { In term of the } \\
\text { sidewalk and its } \\
\text { furniture }\end{array}$} & \multicolumn{2}{|c|}{$\begin{array}{l}\text { In term of } \\
\text { advertisem } \\
\text { ent }\end{array}$} & \multirow{2}{*}{ 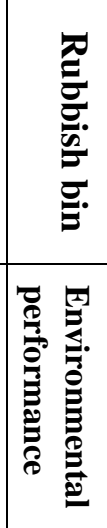 } & \multicolumn{2}{|c|}{$\begin{array}{l}\text { Points } \\
\text { open to the } \\
\text { secondary } \\
\text { lines } \\
\text { leading to } \\
\text { the road }\end{array}$} & \multirow{2}{*}{ 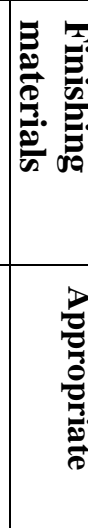 } \\
\hline 电. & 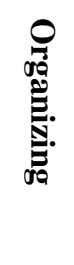 & 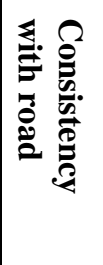 & 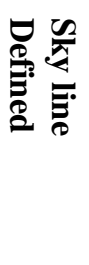 & 兑: & 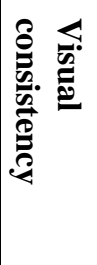 & 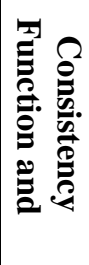 & 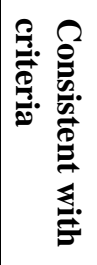 & 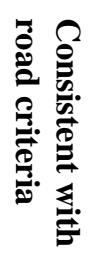 & & 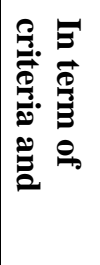 & 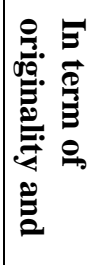 & \\
\hline & & & & & & & & & & & & \\
\hline & & & & & & & & & & & & \\
\hline & & & & & & & & & & & & \\
\hline & & & & & & & & & & & & \\
\hline 20 & 210 & (i) & 201 & & & & & & 20 & 201 & 201 & 201 \\
\hline 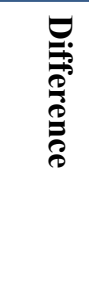 & 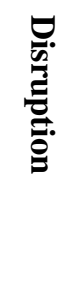 & 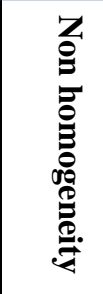 & 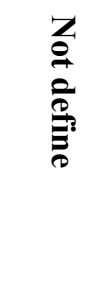 & 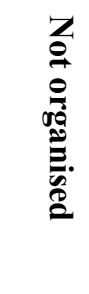 & 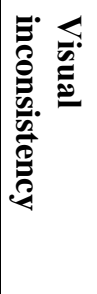 & 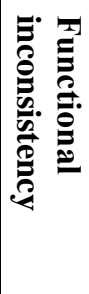 & 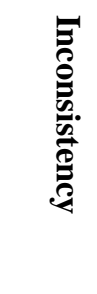 & 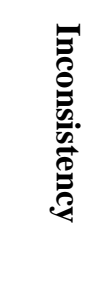 & 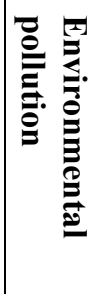 & 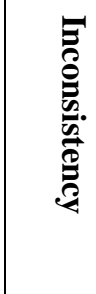 & 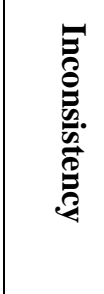 & 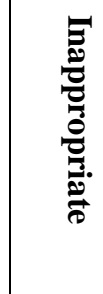 \\
\hline
\end{tabular}

